\title{
O éthos do sujeito negro na literatura brasileira
}

\author{
Cíntia Domingos RIBEIRO \\ (Universidade de São Paulo)
}

RESUMO: O objetivo deste trabalho é depreender o éthos do sujeito negro, na Literatura Brasileira, a partir do processo de figurativização e tematização dos atores de textos que apresentam este sujeito em posições enunciativas distintas: ora como enunciador, ora como enunciado. O corpus é composto pelo conto da literatura negra contemporânea, "Fábrica de fazer vilão" do livro Ninguém é inocente em São Paulo (Ferréz, 2006) e pela novela “Simeão crioulo” do livro As vítimas algozes (1896), de Joaquim Manuel de Macedo, representante do período do Romantismo.

PALAVRAS CHAVE: éthos; literatura negra; enunciação; sujeito negro

ABSTRACT: The purpose of this paper is to extract the éthos of the black individual, in Brazilian Literature, from the figures and themes process of the authors of texts which present this subject in distinct enunciative positions: sometimes as enunciator, sometimes as enunciate. The corpus comprises the contemporary black literature short story "Fábrica de fazer vilão" from the book Ninguém é inocente em São Paulo (Ferréz, 2006) and Joaquim Manuel de Macedo short story "Simeão crioulo" from the book As vítimas algozes (1896), the later as a representative of the Romanticism Period.

KEYWORDS: éthos; black literature; enunciation; black individual 


\section{INTRODUÇão}

O estabelecimento do paralelo entre os textos "Simeão crioulo" e "Máquina de fazer vilão" demonstram como a imagem do sujeito negro na formação da literatura nacional contribuiu para a propagação de formações discursivas acerca deste sujeito que se perpetuaram, logo, presentificaram-se na contemporaneidade.

Desta forma, torna-se pertinente a interface entre a noção de éthos trabalhada por Maingueneau e o processo de figurativização e tematização dos textos escolhidos, pois esse processo também está relacionado à imagem, uma vez que insere o universo sensorial no texto.

\section{CONSIDERAÇÕES SOBRE A LITERATURA NEGRA}

Ao se refletir sobre a construção do éthos do sujeito negro, com base na formação do cânone nacional, cujo movimento literário vigente era o Romântico, pode-se observá-lo em dois posicionamentos distintos e logo duas projeções imagéticas deste sujeito também distintas: numa visão distanciada em que a vivência do negro dentro do processo histórico cultural nacional o apresenta como objeto, tema ou enunciado, o que provoca procedimentos, ideologias, atitudes e estereótipos da "estética branca dominante" (Proença Filho, 2004).

Isto posto, o negro passa a integrar narrativas que tratam mais da escravidão e menos sobre o negro. Assim, o Sistema Literário brasileiro silencia ao longo de sua formação um grupo étnico constituinte do hibridismo do povo brasileiro, silencia uma cultura e suas manifestações. E acaba conferindo um posicionamento, ao sujeito negro, acessório às aspirações da classe dominante difusora dos bens culturais.

Num outro posicionamento, ou seja, numa visão engajada desse sujeito, que ao assumir a "voz" do discurso adquire uma atitude compromissada com a construção do seu próprio percurso e imagem, pode-se observar, dentre outros anseios, o afã de legitimar a sua voz veiculando uma identidade que está intrinsecamente ligada ao lugar social ocupado pelo povo negro no Brasil.

Inserida no conjunto das produções contemporâneas, a Literatura Negra Brasileira, tratada nesse estudo como um conceito semiótico, ou seja, definido por uma rede de relações em que a cor do éthos de enunciador, os temas trabalhados, a cultura manifestada bem como a raça (conceito socialmente construído) são elementos que a definem (Castro, 2006:8), é considerada em relação às escolas literárias do século XX como subliteratura ou ainda militante, pelo fato de apresentar um conteúdo étnico e social de um grupo ${ }^{1}$. Em função disso, esses textos encontram dificuldade de se inserirem no mercado editorial e não são avaliados como literários do ponto de vista da crítica tradicional.

Em contrapartida, não são classificados como militantes os textos que alcançaram o status de canônicos no Romantismo, embora não deixem também de tratar de um conteúdo étnico social pertencente a um grupo. Tal status é conferido a um texto quando esse é utilizado em materiais didáticos, manuais literários, revistas especializadas e outros veículos de comunicação que propagam as formações discursivas de uma dada comunidade. 
O que se pretende com a análise dos textos é, justamente, não perder de vista o fato de que apesar de a Literatura Negra e a Literatura Romântica, esta representada no corpus pela obra de Joaquim Manuel de Macedo, estarem inseridas em um sistema literário, dialogam com enunciatários diferentes e traduzem a subjetividade de enunciadores diferentes. Logo, em seus enunciados, realizam percursos de construção e desconstrução da significação do mundo de modos distintos, valorizando elementos, os quais na análise centram-se no nível discursivo, de acordo com suas respectivas identificações, que se estabelecem por meio da linguagem empregada em cada poética. Nesse sentido, mesmo sob uma aparente neutralidade, toda prática enunciativa projeta no discurso um éthos de enunciador que está associado a um grupo social, fazendo com que este enunciador projete uma imagem do seu outro de acordo com o seu olhar.

\section{A ASSUNÇÃo DA VOZ DO DISCURSO}

A Literatura Contemporânea nomeada como Negra propõe delegar voz a um sujeito pouco retratado na Literatura Brasileira:

A personagem do romance brasileiro contemporâneo é branca. Os branco somam quase quatro quintos das personagens, com uma frequência mais de dez vezes maior do que a categoria seguinte (negros. Em 56,6\% dos romances, não há nenhuma personagem não branca importante. Em apenas 1,6\%, não há nenhuma personagem branca (Dalcastagnè, 2007).

Por conta disso é interessante observar como essas produções literárias, que marcam de forma explícita um grupo étnico-social, tentam legitimar um modo de ser que possui um modo de dizer em virtude dos seus condicionamentos sociais. Délcastagne, discute a problemática da invisibilidade de determinados grupos sociais e conseqüente falta múltiplas identidades culturais, sociais e étnicas que poderiam ser representadas na Literatura Brasileira:

De modo geral, esse tipo de ausência costuma ser creditada à invisibilidade desses mesmos grupos na sociedade brasileira como um todo. Neste caso, os escritores estariam representando justamente essa invisibilidade ao deixar de fora das páginas de seus livros aqueles que são deixados à margem de nossa sociedade. A pergunta que surgia então era se para fazer isso não seria preciso, muito mais que excluir esses grupos de suas histórias, mostras alguma tensão existente, provocada pelos que não parecem estar ali (Dalcastagnè, 2007:21).

Isto significa discutir a diversidade, tanto na presença e constituição dos atores, quanto das vozes das narrativas. Nesse sentido, conferir uma classificação à literatura de acordo com um grupo étnico, como o caso da Literatura Negra, é a partir da voz (ou tom como tratado por Maningueneau) desse grupo conhecer outra percepção do mundo. Os textos dos autores escolhidos marcam as suas percepções, identificações e engajamento quando tratam do sujeito negro. 


\section{4. ÉTHOS: CARÁTER, CORPORALIDADE E VOZ}

Maingueneau trata em seus estudos a questão do éthos como um campo de pesquisa específico, o qual possibilita "refletir sobre o processo de adesão de sujeitos a uma certa posição discursiva” (Maingueneau apud Amossy, 2005:69). Segundo esse autor o discurso mostra, de maneira não explícita, as escolhas lingüísticas e estilísticas realizadas pelo enunciador que configuram a sua imagem projetada no discurso.

O simulacro de objetividade da prática enunciativa mascara a subjetividade do éthos de enunciador, o qual é dotado de um caráter e uma corporalidade, cujas características seriam, respectivamente, “o conjunto de traços psicológicos do enunciador e a maneira de se vestir e de se movimentar no espaço social”. Além disso, integra-se a essa imagem projetada o tom ou voz que dá autoridade ao que é dito. Aproximando da teoria semiótica pode-se verificar a construção de tais características, relacionadas à noção de éthos, nos revestimentos semânticos do nível discursivo.

\section{A CONSTRUÇÃO DO PRÓPRIO PERCURSO E O PERCURSO CONSTRUÍDO}

Embora o conto “Máquina de fazer vilão” esteja inserido num livro que prioriza retratar os excluídos socialmente, há uma representação significativa do negro neste conto, que pode classificá-lo como pertencente à Literatura Negra, até mesmo pelo fato de apresentar um enunciador construído semanticamente no texto como negro.

Percebe-se que é posto em cena uma situação comum na periferia, a blitze da polícia e a sua interação com os moradores do local.

A narrativa trabalha com uma tensão estabelecida entre sujeito e anti-sujeito, respectivamente confirmados pelo revestimento figurativo e temático de /narrador ator/ e /capitão da rota/. Esses dois actantes, detentores da voz, lançam no decorrer do texto figuras que sugerem temas, respectivamente de marginalidade, agressividade, cidadania e amedrontamento, os quais podem ser organizados em alguns grupos lexicais. Segundo Bertrand (2003:186) a isotopia caracteriza-se pela "reiteração de semas ao longo de uma cadeia sintagmática. Essa iteração que é a dos elementos de significação e não das palavras, das figuras e não dos signos, assegura a coesão semântica e a homogeneidade do discurso enunciado". Em "Máquina de fazer vilão” as isotopias vão delineando o olhar dos sujeitos mutuamente, fazendo saltar, dessa forma, o caráter, a corporalidade bem como a voz de cada um conforme as diferentes perspectivas:

- Léxico relacionado ao éthos do actante-sujeito segundo o anti-sujeito: preto/ preto da Etiópia/ macaca/vagabundo/nóia/ neguinho/vaca preta/ montes de bosta.

- Léxico relacionado à violência: porra/ por que o quê, macaca? / cala a boca/ eu falo nesse caralho/ arranca/ joga/ pistola/ matar/ põe fogo/ queima/ atira/ porra/ apaga a luz.

No primeiro agrupamento, por exemplo, a figura /macaca/ está relacionada à animalidade ou zoomorfização assim como a figura /vaca preta/ que além de carregar essa significação da animalidade toca a questão da sexualidade da mulher negra. Outras figuras como /preto da Etiópia/ propõem uma desconstrução, com um teor pejorativo, ao 
corpo do sujeito, o qual é organizado, simbolicamente, de maneira negativa pelo antisujeito.

O anti-sujeito, tematizado como /capitão/ e figurativizado como um homem violento, de acordo com o seu universo axiológico e tendo uma imagem pré-discursiva do sujeito, projeta deste um caráter marginal, ou seja, desprovido de qualquer dote moral ou intelectual, atribuindo-lhe figuras as quais remetem a estereótipos que, ao longo da formação da literatura brasileira, foram atribuídas ao caráter e à corporalidade do sujeito negro, sendo que algumas podem ser encontradas na novela "Simeão crioulo".

Os grupos lexicais relacionados à voz do actante-sujeito projetam uma imagem de resistência à projeção negativa do anti-sujeito, daí a tensão existente entre esses dois actantes:

- Léxico relacionado ao éthos do actante-sujeito segundo ele mesmo: trabalhador/ rap/ guerreiro/ diarista/ desempregado/ pedreiro/ preconceito.

- Léxico relacionado a paixão do actante sujeito: Porque...Porque.../ não paro de olhar a pistola na mão dele/ sim senhor/ ai meu Deus! / chorar/ calado/ mas..., mas capitão...

O actante-sujeito se legitima através do gênero musical rap, cuja acepção é ser um texto declamado de modo ritmado e que apresenta um conteúdo engajado. $\mathrm{O}$ gênero conto nessa narrativa se assemelha ao gênero musical rap. Por conta disso, é construída uma imagem do actante-sujeito de cidadão digno, trabalhador e vítima de condições sociais opressivas (como apresentadas no terceiro grupo lexical). Tal fato também pode ser observado no plano da expressão do texto, pois tanto na voz do actante-sujeito quanto na do anti-sujeito há fonemas oclusivos que sugerem certa explosão ou agressividade, criando, dessa forma, a isotopia temática do tiro.

Num nível mais profundo, o abuso da polícia é representado pela oposição semântica fundamental opressão vs liberdade, a qual vai se confirmando ao longo da narrativa, onde ocorre uma afirmação da opressão e negação da liberdade:

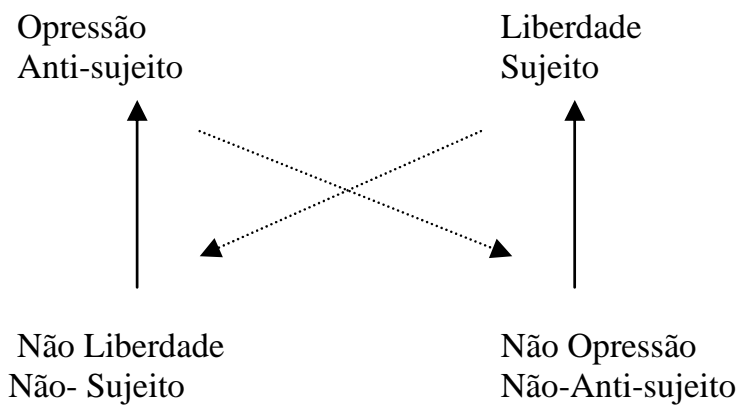

Outra oposição semântica fundamental como vida vs. morte também pode ser encontrada nesse texto, no qual vai sendo afirmada a vida e negada a morte na medida em que o anti-sujeito não se encontra na narrativa. Assim, o éthos do oprimido (sujeito) 
vai se configurando de uma maneira que não fica na ordem do dito, mas sim do mostrado pela interação entre os actantes.

Percebe-se que mesmo em um ambiente figurativizado pelo bar e tematizado como periférico, dentro da proposta da Literatura Negra o sujeito negro não assume um caráter, uma corporalidade estigmatizada, pois tenta legitimar seu modo de dizer associado, nesse conto, ao rap.

Ao passo que o fragmento da novela "Simeão crioulo", que pode ser encontrado nos anexos, mesmo se tratando de um texto que se mirava nas propostas abolicionistas, tratava mais da escravidão e menos da subjetividade do sujeito negro, marcando dessa forma uma visão distanciada que contribuiu para a disseminação de estereótipos negativos acerca desse sujeito, logo, uma desconstrução semiótica do seu universo simbólico:

Caráter e corporalidade do fiador (enunciador) apóiam-se, então, sobre um conjunto difuso de representações sociais valorizadas ou desvalorizadas, de estereótipos sobre os quais a enunciação se apóia e,por sua vez, contribui para reforçar ou transformar . Esses estereótipos culturais circulam nos registros mais diversos da produção semiótica de uma coletividade: livros de moral, teatro, pintura, escultura, cinema, publicidade (Amossy, 2005:72).

O texto de Macedo se apresenta mais figurativo do que temático por conta do seu caráter descritivo criando um simulacro de realidade, o que está de acordo com a formatação do conto que apresenta uma introdução, um desenvolvimento e uma conclusão como uma tese, gerando um efeito de sentido de objetividade. Observando a escolha do léxico para a organização dos temas subjacentes às figuras, pode-se organizar três grupos lexicais que possuem uma conexão e lançam temas, respectivamente, de ambiente subversivo, doença e animalidade:

- Venda: esquálida / medonha/ criminosa / atroz/ Perigosa / repugnante.

- Escravidão: úlcera / pus / cancro/ podridão/ loucura / sofrimento.

- Escravo: embebedam-se / espancam-se/ indecente/ selvagens/ desgraçados/ embriaguez/ desordem/abjeção/ desavergonhamento.

A pessoa, o espaço e o tempo projetados pela sintaxe discursiva também são tematizados e figurativizados. Assim, a pessoa (ele) é tematizada como escravo e figurativizada com elementos próprios de um animal, como mencionado anteriormente. O espaço é tematizado como um lugar perigoso e figurativizado com propriedades negativas (as quais não são expressas nesse fragmento), mas essa venda não é particularizada, poderia ser qualquer lugar onde os escravos e outros marginalizados poderiam se relacionar. O tempo é tematizado pela escravidão e figurativizado com elementos próprios dessa época.

As oposições semânticas fundamentais são as mesmas do conto "Máquina de fazer vilão", pois as estruturas opressivas se mantiveram nos textos. 


\section{CONSIDERAÇõEs FinAIS}

As escolhas lexicais acerca do sujeito negro neste texto demonstram com a formação do cânone literário nacional, contribuiu para o processo de estereotipia do sujeito negro. O conceito de estereótipo é caracterizado por Maingueneau da seguinte forma:

Representação coletiva cristalizada é uma construção de leitura, uma vez que ele emerge somente no momento em que um alocutário recupera, no discurso, elementos espalhados e frequentemente lacunares, pra reconstruí-los em função de um modelo cultural preexistente. Pode-se então dizer que o estereótipo, como o clichê, depende do cálculo interpretativo do alocutário e de seu conhecimento enciclopédico. Constitui-se como topoi ou lugares-comuns, uma das formas adotadas pela doxa, ou conjunto de crenças e opiniões partilhadas que fundamentam a comunicação e autorizam a interação verbal (Charaudeau \& Maingueneau, 2006:215).

Essas representações puderam ser demonstradas nos textos através das figuras lançadas de acordo com a perspectiva de cada sujeito e como cada um fora e é representado literariamente.

O texto da Literatura Negra tem como uma de suas propostas, realizar uma representação literária efetiva do sujeito negro euforizando elementos do universo simbólico desse indivíduo.

Ao expor os estereótipos que foram relacionados ao sujeito negro a Literatura Negra estabelece uma perspectiva enunciativa oposta ao que se fazia no passado, criando um efeito de sentido de resistência as formações discursivas de outrora que se ecoaram na contemporaneidade, a fim de legitimar a sua voz na enunciação do seu próprio percurso. Por isso, é interessante observar que tipo de estratégias discursivas essa Literatura utiliza para introduzir outras vozes no espaço literário nacional.

\section{NOTAS}

${ }^{1}$ CUTI, Luiz. Negros em Contos. Belo Horizonte: Mazza Edições, 1996.

\section{REFERÊNCIAS BIBLIOGRÁFICAS}

AMOSSY, Ruth. Imagens de si no discurso. São Paulo: Contexto, 2005.

BERTRAND, Denis. Caminhos da semiótica literária. Tradução do Grupo CASA. Bauru, SP: EDUSC, 2003.

CÂNDIDO, Antônio. Formação da literatura brasileira. São Paulo,

CASTRO, Silvia Regina Lorenso. Corpo e erotismo em Cadernos negros: a reconstrução semiótica da liberdade. São Paulo, 2006.

CHARAUDEAU, P. \& MAINGUENEAU, D. Dicionário de análise do discurso. Tradução de F. Komesu. São Paulo: Contexto, 2006.

DALCASTAGNÈ, Regina. "A personagem do romance brasileiro Comtemporâneo: 1990-2004”. Cronópios. [online] Disponível na Internet via WWW.URL: http://www.cronopios.com.br/anexos/regina_dalcastagne.swf. Editor Edson Cruz. 3 de maio de 2007. 
DALCASTAGNÈ, Regina. Entre fronteiras e cercados de armadilhas: problemas de representação na narrativa brasileira contemporânea. Brasília: Editora UNB, 2005.

FIORIN, José Luiz. Elementos de análise do discurso. São Paulo: Contexto, 2005.

GREIMAS, A. J. \& COURTÉS, J. Dicionário de semiótica. Trad. A. D. Lima et alii. São Paulo: Cultrix, s/d [1983].

MACEDO, Joaquim Manuel de. As vítimas algozes: quadros da escravidão. São Paulo: Scipione, 1991.

PROENÇA FILHO, Dominício. “A Trajetória do Negro na Literatura Brasileira”. In: Estudos avançados 50, dossiê O negro no Brasil. São Paulo: Instituto de Estudos Avançados, 2004.

VÁRIOS AUTORES. Reflexões sobre a literatura afro-brasileira. São Paulo: Quilombhoje, 1985.

\section{Anexo}

[...] Desprezível e nociva durante o dia, a venda é esquálida, medonha, criminosa e atroz durante a noute: os escravos, que aí então se reúnem, embebedam-se, espancam-se, tornando-se muitos incapazes de trabalhar na manhã seguinte; misturam as rixas e as pancadas com a conversação mais indecente sob o caráter e a vida de seus senhores, cuja reputação é ultrajada ao som de gargalhadas selvagens: inspirados pelo ódio, pelo horror, pelos sofrimentos inseparáveis da escravidão, se expandem em calúnias terríveis que às vezes chegam até a honra das esposas e das filhas dos senhores; atiçam a raiva a que todos eles têm dos feitores, contando histórias lúgubres de castigos exagerados e de cruelíssimas vinganças, a cuja idéia se habituam, em sua credulidade estúpida e ilimitada esses desgraçados escutam boquiabertos a relação dos prodígios do feitiço, e se emprazam para as reuniões noturnas dos feiticeiros; e uns finalmente aprendem com outros mais sabidos a conhecer plantas maléficas, raízes venenosas que produzem a loucura ou dão a morte, e tudo isto e muito mais ainda de envolta com a embriaguez, com a desordem, com o quadro da abjeção e do desavergonhamento já natural nas palavras, nas ações, nos gozos do escravo.

[...] Não é possível que haja escravos sem todas as conseqüências escandalosas da escravidão: querer a úlcera sem o pus, o cancro sem a podridão é loucura ou capricho infantil.

Perigosa e repugnante por certo, e ainda assim não das mais formidáveis conseqüências da escravidão, a venda de que estou falando é inevitável: porque nasce da vida, das condições, e das exigências irresistíveis da situação dos escravos.

A venda é o espelho que retrata ao vivo o rosto e o espírito da escravidão.

(Macedo, 1991:07) 


\section{Como citar este artigo:}

RIBEIRO, Cíntia Domingos. O éthos do sujeito negro na literatura brasileira. Estudos Semióticos. [online] Disponível na Internet via WWW.URL: http://www.fflch.usp.br/dl/semiotica/es. Editor Peter Dietrich. Número 4, São Paulo, 2008.

Acesso em "dia/mês/ano". 